\title{
SELEÇÃO IN VITRO DE FUNGOS ENDOFÍTICOS PARA O CONTROLE BIOLÓGICO DE Botrytis cinerea EM Eucalyptus benthamii
}

\author{
José Antonio Sbravatti Júnior ${ }^{1}$, Celso Garcia Auer², Ida Chapaval Pimentel ${ }^{3}$, \\ Álvaro Figueredo dos Santos ${ }^{2}$, Bruno Schultz \\ ${ }^{1}$ Eng. Florestal, Mestrando em Ciências Florestais, UFPR, Curitiba, Paraná, Brasil - juniorasbi@ hotmail.com \\ ${ }^{2}$ Eng. Florestal, Dr., Embrapa Florestas, Colombo, Paraná, Brasil - celso.auer@embrapa.br; alvaro.santos@embrapa.br \\ ${ }^{3}$ Eng $^{\mathrm{a}}$ Agrônoma, Dr ${ }^{\mathrm{a}}$., Depto. de Patologia Básica, UFPR, Curitiba, Paraná, Brasil - ida @ufpr.br \\ ${ }^{5}$ Eng. Florestal, M.Sc., Doutorando em Sensoriamento Remoto, INPE, São José dos Campos, São Paulo, Brasil - \\ schultz.florestal@gmail.com
}

Recebido para publicação: 28/03/2012 - Aceito para publicação: 25/02/2013

\begin{abstract}
O Eucalyptus benthamii é uma das principais espécies de eucalipto plantadas na região Sul do Brasil, por sua resistência a geadas e por seu uso na produção florestal de madeira para fins energéticos. Na produção de mudas, uma das principais doenças ocorrentes em viveiros é o mofo-cinzento, causado pelo fungo Botrytis cinerea. Uma das alternativas para o controle dessa doença é o controle biológico com fungos endofíticos, os quais podem competir com os patógenos foliares de mudas de eucalipto. O objetivo deste trabalho foi isolar os fungos endofíticos provenientes de mudas de E. benthamii, identificá-los e selecionálos para o controle de $B$. cinerea. Eles foram isolados do interior de tecidos vegetais desinfectados, identificados de acordo com critérios macro e micromorfológicos e classificados a partir de testes de controle biológico in vitro. Os resultados evidenciaram o potencial antagonista dos fungos Aspergillus sp., Penicillium sp. e Trichoderma sp. Nenhum desses fungos causou lesões em mudas de E. benthamii.

Palavras-chave: Mofo-cinzento; eucalipto; viveiro.
\end{abstract}

Resumo

\begin{abstract}
In vitro selection of endophytes for biological control of Botrytis cinerea in Eucalyptus benthamii. Eucalyptus benthamii is one of the main eucalypt species planted in Southern Brazil, due to its resistance to frost and its use in the production of forest wood for energy purposes. During the production of seedlings, the main disease occurring in forest nurseries is gray-mold caused by the fungus Botrytis cinerea. One alternative for control this disease is biological control with fungal endophytes, which can compete with the foliar pathogens of eucalypt seedlings. The objective of this study was to isolate endophytic fungi from seedlings of Eucalyptus benthamii, identify and select them for $B$. cinerea control. These were isolated from the interior of disinfected plant tissues, identified according to macro and micromorphological criteria, and based on tests of biological control in vitro. The results revealed the potential antagonist of Aspergillus sp., Penicillium sp. and Trichoderma sp. No fungi caused lesions in E. benthamii seedlings.
\end{abstract}

Keywords: Gray-mold; eucalypt; nursery.

\section{INTRODUÇÃO}

Eucalyptus benthamii Maiden et Cambage é natural da Austrália, encontrado em áreas limitadas ao oeste de Sydney, em planícies com solos férteis ao longo do rio Nepean e seus afluentes. Essa exigência silvicultural tornou a espécie vulnerável durante a expansão da fronteira agrícola, colocando-a em condição de espécie ameaçada de extinção no seu país de origem. Levantamentos recentes mostram a ocorrência de uma pequena população e de alguns indivíduos isolados ao longo do Rio Nepean, entre as localidades de Wallacia e Camden, e de uma população maior, localizada entre $33^{\circ} 49^{\prime}$ latitude sul e $150^{\circ} 22^{\prime}$ longitude oeste, em Kedumba Creek (HIGA; PEREIRA, 2003).

No Brasil, a espécie foi introduzida via semente pela Embrapa Florestas na década de 80, sendo que as mudas foram plantadas no ano de 1988, originando uma área de produção de sementes (KRATZ et al., 2011). Na região Sul do país, o clima é um fator limitante para a produção florestal, fazendo-se 
necessário o cultivo de espécies que apresentem maior tolerância ao frio. Em virtude da rapidez de crescimento, da boa forma do fuste, rusticidade e resistência às geadas, o Eucalyptus benthamii destaca-se entre as espécies do gênero. A crescente demanda por mudas estimula estudos mais detalhados sobre quais aspectos podem contribuir para o desenvolvimento de E. benthamii em condições de viveiro (SCHULTZ, 2011).

De acordo com Auer e Santos (2011), durante a produção de mudas de eucalipto em viveiros florestais, podem ocorrer ataques de patógenos, principalmente de fungos, causando doenças importantes que reduzem a produção, além de causarem significativos impactos econômicos, de acordo com a espécie atacada e da época do ano.

As mudas de eucalipto estão sujeitas a mais de uma dezena de doenças fúngicas. Entre as principais doenças que ocorrem em viveiros de eucalipto na região Sul do Brasil, pode-se destacar o mofo-cinzento, causado pelo agente etiológico Botrytis cinerea Pers.: Fr, em função da elevada umidade, juvenilidade e proximidade das mudas (BIZI, 2006).

Segundo Alfenas et al. (2009), o B. cinerea (mofo-cinzento) causa morte de mudas em reboleiras ou distribuídas aleatoriamente nos canteiros. Posteriormente, surge abundante esporulação de coloração cinza sobre estacas, miniestacas ou microestacas mortas, folhas e brotações infectadas.

Essa doença pode causar um alto percentual de perdas, sendo necessário algum tipo de controle, normalmente feito por meio de produtos químicos e por manejo integrado. De acordo com Bizi et al. (2005), o controle químico em viveiros florestais utiliza os mesmos produtos recomendados para a área agrícola, no entanto não existem fungicidas registrados para a cultura de eucalipto.

Considerando a constante demanda por parte dos viveiristas e produtores por recomendações de controle, aliada à ausência de produtos químicos registrados, torna-se interessante um direcionamento das pesquisas para o controle alternativo dessas doenças (BIZI, 2006).

Uma das alternativas é o controle biológico com microrganismos endofíticos, que são agentes antagonistas capazes de penetrar na planta e se disseminar sistematicamente no hospedeiro sem causar doença, mas impedindo o avanço dos patógenos. (ARAÚJO et al., 2002). Para B. cinerea, existem alguns relatos de estudos com microrganismos para controle biológico em condições brasileiras, porém nenhum deles trata dos fungos endofíticos.

Com essa perspectiva, o objetivo deste trabalho foi isolar os fungos endofíticos provenientes de mudas de $E$. benthamii, identificá-los e selecioná-los conforme seu potencial para controle do patógeno $B$. cinerea.

\section{MATERIAL E MÉTODOS}

O estudo foi realizado entre outubro de 2009 e junho de 2010, no Laboratório de Microbiologia, Patologia e Parasitologia da Universidade Federal do Paraná e no Laboratório de Patologia Florestal da Embrapa Florestas, respectivamente localizados nas cidades de Curitiba e Colombo, PR.

\section{Material vegetal utilizado}

Foram utilizadas 30 mudas sadias de E. benthamii com três meses de idade, procedentes de viveiro comercial, formadas com sementes de área de produção de sementes (APS), localizada no município de Guarapuava, PR. As mudas foram produzidas em tubetes de $50 \mathrm{~cm}^{3}$ preenchidos com substrato comercial à base de vermiculita e casca de pínus. Na casa de vegetação, as mudas foram acondicionadas em bandejas e mantidas com irrigação manual, apenas molhando-se o substrato.

Os lotes de mudas sadias foram utilizados para o isolamento dos fungos endofíticos e também para os testes de inoculação com o patógeno Botrytis cinerea.

\section{Isolamento dos fungos endofíticos}

Inicialmente, procedeu-se à confecção de discos de folhas contendo a nervura central e de segmentos de hastes das mudas de E. benthamii, cada amostra individual com cerca de $1 \mathrm{~cm}^{2}$ de área. Ao se tratar de fungos endofíticos, é necessário realizar uma técnica de desinfecção superficial, que foi realizada utilizando o seguinte protocolo, descrito em Araújo et al. (2002):

a) lavagem das amostras em água corrente para a retirada de resíduos de poeira e solo;

b) corte das amostras em fragmentos; 
c) imersão em solução de álcool $70 \%$ por 1 minuto;

d) imersão em solução de hipoclorito de sódio $1 \%$ por 3-4 minutos;

e) imersão em solução de álcool $70 \%$ por 30 segundos;

f) enxágue por duas vezes em água destilada e esterilizada.

Após esse processo, 3 discos foliares e 3 segmentos de haste de cada muda foram colocados em placas de Petri contendo meio BDA (ágar-batata dextrosado comercial, $39 \mathrm{~g} ; 1000 \mathrm{~mL}$ ), com a parte superior da folha virada para cima. As placas foram incubadas em BOD a $25{ }^{\circ} \mathrm{C}$, no escuro. Com o surgimento das colônias, elas foram purificadas para posterior identificação. Parte dos isolados foi transferida individualmente para tubos de ensaio contendo BDA, cultivados por sete dias e recobertos com óleo mineral estéril, identificados e mantidos para preservação em refrigeração a $4{ }^{\circ} \mathrm{C}$ no Laboratório de Patologia Florestal da Embrapa Florestas.

\section{Identificação taxonômica dos fungos endofíticos}

Primeiramente, os isolados foram separados em grupos denominados morfotipos, conforme a morfologia macroscópica. Após essa primeira divisão em morfotipos, foi realizada a técnica de microcultivo (KERN; BLEVINS, 1999) de uma colônia de cada grupo morfologicamente semelhante. Lâminas de sete e 14 dias obtidas do microcultivo foram utilizadas para a identificação dos fungos e sua classificação, realizada através de observações de corpos de frutificação ao microscópio óptico (400x) e da utilização de literatura especializada (KLICH; PITT, 1988; BARNETT; HUNTER, 1987; LARONE, 1987; HAZEN et al., 1973; MENEZES; OLIVEIRA, 1993; KERN, 1988; HERRERA; ULLOA, 1990).

\section{Técnica do microcultivo (KERN; BLEVINS, 1999)}

Para essa técnica, foram utilizadas placas de Petri esterilizadas, contendo em seu interior uma lâmina e um pedaço de algodão. Um cubo de aproximadamente $1 \mathrm{~cm}^{3}$ de meio de cultura BDA foi cortado e colocado sobre uma lâmina contida no interior da placa. O fungo é repicado em todos os lados do cubo, o qual será posteriormente coberto por uma lamínula esterilizada. O algodão no interior é umedecido com água destilada esterilizada e a placa mantida em estufa incubadora por 7 a 14 dias, a aproximadamente $28{ }^{\circ} \mathrm{C}$. Após o tempo determinado, a lamínula foi retirada e colocada sobre outra lâmina limpa contendo uma gota de lactofenol de Amann, sendo as bordas vedadas com esmalte. As lâminas preparadas foram observadas em microscópio óptico.

\section{Obtenção de inóculo de Botrytis cinerea}

$\mathrm{O}$ isolado utilizado nos experimentos foi obtido a partir de mudas de E. benthamii doentes, procedentes de viveiro comercial. O patógeno foi isolado pelo método direto, ou seja, sob a lupa e com o auxílio de um estilete, foram recolhidos micélio e conídios do patógeno, que posteriormente foram transferidos para placas de Petri com meio BDA. Foram preparados três isolados monospóricos, multiplicados também em meio BDA, e mantidos em câmara BOD à temperatura de $25^{\circ} \mathrm{C}$ (ALFENAS et al., 2009), até produzirem conídios para a inoculação. Esse isolado foi selecionado e utilizado nos experimentos por apresentar um bom crescimento e esporulação in vitro.

\section{Pareamento de culturas}

Nessa etapa, foi utilizada a técnica de cultura pareada (MARIANO, 1993) para avaliação do antagonismo dos isolados endofíticos contra fitopatógenos, respeitando-se o tempo de crescimento dos isolados e fitopatógenos avaliados. Para este estudo, foram escolhidos somente os endofíticos identificados, em número de nove isolados.

Os discos contendo micélio e/ou conídios dos isolados endofíticos e do patógeno foram obtidos de colônias crescidas em meio BDA, durante sete dias, incubadas em câmara BOD, com temperatura de $25{ }^{\circ} \mathrm{C}$. Após esse período, os discos foram retirados da borda das colônias, com diâmetro inicial de dez milímetros. Os discos do endófito e do patógeno foram posicionados em extremidades opostas da placa de Petri contendo meio BDA e novamente incubados em câmara BOD por um período de 14 dias. Foram realizadas duas avaliações, uma aos sete dias e a outra no final do período, equivalente ao intervalo de tempo em que o micélio do patógeno atingiu o crescimento máximo na presença dos fungos antagônicos. Após o período de incubação, a análise foi realizada por meio da medição dos diâmetros médios das 
culturas. Neste ensaio, utilizou-se um delineamento inteiramente casualizado com cinco repetições, sendo que cada placa de Petri constituiu-se em uma unidade experimental. Os testes estatísticos foram realizados pelo Programa Assistat 7.6 (SILVA; AZEVEDO, 2009).

Para determinar a porcentagem de inibição do crescimento do patógeno, mediu-se o diâmetro das colônias, subtraindo-se o diâmetro do disco de micélio inicial (QUIROGA et al., 2001) e calculada de acordo com Edginton et al. (1971), pela fórmula:

- Porcentagem de inibição $(\mathrm{PI} \%)=(\mathrm{Dc}-\mathrm{Dt} / \mathrm{Dc}) \times 100$

em que Dc é o diâmetro médio da colônia do patógeno das placas testemunhas (sem antagonista) e Dt é o diâmetro médio da colônia do patógenos frente ao antagonista (isolado endofítico).

\section{Testes de patogenicidade dos fungos endofíticos}

Os fungos endofíticos selecionados nos testes de antagonismo foram testados quanto à sua patogenicidade ao E. benthamii. Para esse teste, empregou-se metodologia similar aos estudos de patogenicidade em Ilex e Eucalyptus feitos por Lau e Grigoletti Júnior (1997). Foram utilizadas dez mudas de E. benthamii por tratamento, sadias, vigorosas e uniformes em altura e número de folhas, que foram distribuídas em caixas plásticas $(40$ x 60 x $35 \mathrm{~cm})$. Uma camada aproximada de $10 \mathrm{~cm}$ de vermiculita expandida umedecida foi colocada no fundo das caixas, para separá-las, mantê-las em posição vertical e para facilitar a formação da câmara úmida. As caixas permaneceram encobertas com tampas, formando a câmara úmida, durante o período de incubação de 14 dias, em casa de vegetação, sem controle de temperatura.

A inoculação dos fungos endofíticos F3 (Aspergillus sp.), F6 (Trichoderma sp.) e F29 (Penicillium sp.), selecionados nos testes de antagonismo, foi feita através de pulverização com uma suspensão de esporos, obtida por meio da lavagem com água ultrapurificada de colônias cultivadas em placas de Petri com meio BDA, durante vinte dias, com temperatura de $25{ }^{\circ} \mathrm{C}$, em condições de laboratório. A concentração de esporos da suspensão do isolado $\mathrm{F} 3$ foi de $5,5 \times 10^{4}$ conídios $/ \mathrm{mL}$, de $2,4 \times 10^{4}$ conídios/mL para o isolado F29 e de $2,7 \times 10^{4}$ conídios $/ \mathrm{mL}$ para o isolado F6.

A avaliação da patogenicidade foi feita dez dias após a inoculação dos fungos endofíticos, verificando-se a presença de sintomas. O reisolamento foi feito em meio BDA, para a confirmação da patogenicidade do endófito testado.

\section{RESULTADOS E DISCUSSÃO}

\section{Isolamento dos fungos endofíticos}

Foram isolados 62 fungos endofíticos, agrupados em 11 morfotipos, dos quais foram identificados somente nove isolados: Alternaria sp., Amblyosporium sp., Aspergillus sp., Penicilium sp., Rhizoctonia sp. e Trichoderma sp., presentes em discos foliares, e Pestalotiopsis sp. e Phoma sp., presentes em segmentos de hastes. $\mathrm{O}$ restante dos fungos não foi identificado, por falta de estruturas reprodutivas. Destaque dado para o fungo Helminthosporium sp., que foi identificado nos dois tipos de amostras (Tabela 1). A maioria dos isolados foi obtida de discos de folhas (35), e o restante dos segmentos de hastes (27).

Tabela 1. Relação de fungos endofíticos isolados de folhas e hastes de mudas de Eucalyptus benthamii.

Table 1. List of endophytic fungi isolated from leaves and stems of Eucalyptus benthamii.

\begin{tabular}{lcccc}
\hline Antagonista & Fungo & Número de isolados & Frequência (\%) & Origem \\
\hline F-13 & Alternaria sp. & 16 & 25,83 & Disco foliar \\
F-30 & Amblyosporium sp. & 01 & 1,61 & Disco foliar \\
F-3 & Aspergillus sp. & 02 & 3,22 & Disco foliar \\
H-9 & Helminthosporium sp. & 35 & 56,45 & Segmento de haste/ \\
F-29 & Penicillium sp. & 04 & 6,45 & Disco foliar \\
H-18 & Pestalotiopsis sp. & 01 & 1,61 & Disco foliar \\
H-22 & Phoma sp. & 01 & 1,61 & Segmento de haste \\
F-14 & Rhizoctonia sp. & 01 & 1,61 & Segmento de haste \\
F-6 & Trichoderma sp. & 01 & 1,61 & Disco foliar \\
\hline
\end{tabular}

Teste de antagonismo 
Os testes realizados através do método in vitro revelaram o potencial antagonista de alguns fungos endofíticos contra $B$. cinerea, constatado através da sobreposição das colônias de Aspergillus sp., Penicillium sp. e Trichoderma sp., que reduziram o crescimento micelial do patógeno (Tabela 2). Contudo, o pareamento de alguns endofíticos apresentou resultados negativos, ou seja, estimulou o crescimento da colônia de B. cinerea (Tabela 2). Esse resultado contraditório pode ser explicado por sinergia decorrente da produção de substâncias estimuladoras entre fungos (AZEVEDO, 1998).

Especificamente contra o mofo-cinzento, Sanfuentes e Ferreira (1996) testaram Gliocladium roseum (Clonostachys rosea), Penicillium sp., Trichoderma harzianum, T. viride e dois isolados de Trichoderma sp. para a supressão de B. cinerea em mudas de eucalipto. O melhor resultado foi obtido no tratamento com G. roseum.

Mercader et al. (2006) isolou 71 fungos endofíticos de Eucalyptus globulus e os testou em ensaios de biocontrole in vitro contra Botrytis cinérea. Entre eles, Clonostachys sp., Penicillium sp. e 4 isolados de Trichoderma sp. apresentaram bons resultados na supressão das colônias de B. cinerea, confirmando a sua eficácia como agentes de biocontrole do fungo causador do mofo-cinzento.

As atividades antagonistas para reduzir a colonização e esporulação do patógeno nessas condições demonstram que esses fungos possuem uma rápida germinação e iniciam a atividade antagônica de forma oportuna (SUTTON; PENG, 1993).

Apesar de obter bons resultados da atividade antagônica in vitro, isso não corresponde à garantia da redução de doenças no campo (BETTIOL, 1991). No entanto, Kupper et al. (2003) relata que diversas vezes a eficácia dos antagonistas in vitro ou em casa de vegetação pode ser insuficiente para estabelecer o limiar de população exigida para um biocontrole no campo, mas pode servir como indicativo da viabilidade no controle de fitopatógenos sob condições naturais de infecção.

Tabela 2. Inibição do crescimento micelial de Botrytis cinerea após teste de pareamento em meio BDA com nove endofíticos isolados de folhas e hastes de E. benthamii.

Table 2. Inhibition of Botrytis cinerea mycelial growth after pairings test on PDA with nine endophytic isolated from leaves and stems of E. benthamii.

\begin{tabular}{lcc}
\hline Fungos testados & Diâmetro médio das colônias do fitopatógeno $\mathbf{( m m})$ & Percentual de inibição $\mathbf{( \% )}$ \\
\hline Trichoderma sp. & $26,2 \mathrm{a}^{*}$ & 16,5 \\
Penicillium $\mathrm{sp}$. & $26,6 \mathrm{ab}$ & 6,36 \\
Aspergillus $\mathrm{sp}$. & $30 \mathrm{~b}$ & 4,45 \\
Alternaria sp. & $32,4 \mathrm{c}$ & 0,8917 \\
Pestalotiopsis sp. & $37,6 \mathrm{c}$ & 0,8917 \\
Testemunha & $31,4 \mathrm{c}$ & 0 \\
Rhizoctonia sp. & $42 \mathrm{c}$ & $-33,7$ \\
Helminthosporium sp. & $43,4 \mathrm{c}$ & $-38,2$ \\
Amblyosporium $\mathrm{sp}$. & $51 \mathrm{c}$ & $-62,4$ \\
Phoma sp. & $54,2 \mathrm{c}$ & $-72,6$ \\
\hline
\end{tabular}

Médias seguidas por letras distintas diferem entre si, pelo teste de Duncan, ao nível de 5\% de significância. Percentual de inibição negativo significa que houve estímulo ao crescimento do patógeno. CV: $11,1 \%$.

\section{Testes de patogenicidade}

As inoculações com os endofíticos Aspergillus sp., Penicillium sp. e Trichoderma sp. realizadas em mudas de E. benthamii não produziram lesões foliares após o período de incubação. Desse modo, verificou-se que esses fungos não são patogênicos em folhas de $E$. benthamii e podem ser utilizados para testes de antagonismo em viveiros florestais. Segundo Azevedo (1998), é difícil estabelecer um limite definido entre microrganismos endofíticos e patogênicos, sendo que algumas vezes certos endofíticos que não causam sintomas aparentes em determinado hospedeiro podem agir como patógenos em outros. A partir disso, os testes de patogenicidade visaram evidenciar qual seriam os efeitos na muda após a inoculação dos fungos endofíticos selecionados nos testes de antagonismo.

A partir dos testes de antagonismo e da ausência de patogenicidade dos endofíticos testados, pôde-se evidenciar o potencial de controle para uma próxima etapa, que englobaria os testes in vivo e sua comparação com um fungicida. 


\section{CONCLUSÕES}

Os fungos endofíticos inibiram o crescimento in vitro de Botrytis cinerea e não causaram lesões foliares em Eucalyptus benthamii, podendo ser testados para o controle do mofo-cinzento em mudas dessa espécie. Destes, podem ser indicados como potenciais controladores os fungos Aspergillus sp., Penicillium sp. e Trichoderma sp.

\section{REFERÊNCIAS}

ALFENAS, A. C.; ZAUZA, E. A. V.; MAFIA, R. G.; ASSIS, T. F. Clonagem e doenças de eucalipto. Viçosa, MG: UFV, 2009. 500 p.

ARAÚJO, W. L.; LIMA, A. O. S.; AZEVEDO, J. L.; MARCON, J.; KUKINSKY-SOBRAL, J.; LACAVA, P. T. Manual: isolamento de microrganismos endofíticos. Piracicaba: CALQ, 2002. 86 p.

AUER, C. G.; SANTOS, A. F. dos. Doenças em eucaliptos destinados à produção de energia na região Sul do Brasil. Pesquisa Florestal Brasileira, Colombo, v. 31, p. 373 - 379, 2011.

AZEVEDO, J. L. Micro-organismos endofíticos. In: MELLO, I. S. and AZEVEDO, J. L. (ed.). Ecologia microbiana. Embrapa Meio Ambiente. Jaguariúna, 1998. p. 17 - 137.

BARNETT, H. C.; HUNTER, B. B. Illustrated genera of imperfect fungi. 3. ed., Minneapolis: Burgess Publications, 1987. p. 218.

BETTIOL, W. Seleção de microrganismos antagônicos a fitopatógenos. In: Bettiol, W. org. Controle Biológico de Doenças de Plantas. Embrapa - CNPDA. Jaguariúna, 1991. p. 223 - 236.

BIZI, R. M. Alternativa de controle do mofo-cinzento e do oídio em mudas de eucalipto. $74 \mathrm{f}$. Dissertação (Mestrado em Ciências Agrárias) - Universidade Federal do Paraná, Curitiba, 2006.

BIZI, R. M.; GRIGOLETTI JÚNIOR, A.; AUER, C. G. Seleção de fungicidas para controle de oídio em eucalipto. Boletim de pesquisa florestal - Unidade Regional de Pesquisa Florestal, Embrapa Florestas, Colombo/PR, v. 51, n. jul./dez., p. 165 - 170, 2005.

EDGINTON, L. V.; KNEW, K. L.; BARRON, G. L. Fungitoxic spectrum of benzimidazole compounds. Phytopathology, Saint Paul, v. 62, n. 7, p. 42 - 44, 1971.

HAZEN, E. L.; GORDON, M. A.; REED, F. C. Laboratory identification of pathogenic fungi simplified. 3 ed, Springfield (USA): Charles C. Thomas, 1973.

HERRERA, T.; ULLOA, M. El reino de los hongos. Micología básica y aplicada. 1. ed, México, 1990.

HIGA, R. C. V.; PEREIRA, J. C. D. Usos potenciais do Eucalyptus benthamii Maiden et Cambage. Comunicado Técnico no. 100 Embrapa Florestas, Colombo, 4 p., 2003.

KERN, M. E. Medical mycology: a self-instructional text. 3. ed. Philadelphia: F.A. Davis Company, 1988.

KERN, M. E.; BLEVINS, K. S. Micologia médica - Texto e Atlas. 2. ed, São Paulo: Editoral Premier, 1999.

KLICH, M. A.; PITT, J. I. Common Aspergillus species and their teleomorphs. Australia: Commonwealth Scientific and Industrial Research Organization, 116 p., 1988.

KRATZ, D. Substratos renováveis para produção de mudas de Eucalyptus benthami Maiden et Cambage e Mimosa scabrella Benth.118 f. Dissertação (Mestrado em Ciência Florestal) - Universidade Federal do Paraná, Curitiba, 2011. 
KUPPER, K. C.; FERNANDES, N. G.; GOES, A. Controle biológico de Colletotrichum acutatum, agente causal da queda prematura dos frutos cítricos. Fitopatologia Brasileira, Brasília, v. 28, n. 3, p. $251-257,2003$.

LARONE, D. H. Medically important fungi: a guide to identification. 2. ed. New York: Elsevier, 1987.

LAU, D.; GRIGOLETTI JÚNIOR, A. Patogenicidade de Cylindrocladium spathulatum em espécies de Ilex e Eucalyptus. Fitopatologia Brasileira, Brasília. v. 22., Supl., p. 274, 1997.

MARIANO, R. L. R. Métodos de seleção in vitro para o controle microbiológico de patógenos de plantas. Revisão Anual de Patologia de Plantas, v. 1, p. 69 - 409, 1993.

MENEZES, M.; OLIVEIRA, S. M. A. Fungos fitopatogênicos. Pernambuco: UFRPE (imprensa Universitária), 1993. 277 p.

MERCADER, G. M.; FLORES, S. Z.; VARGAS, G. G.; STOWASSER, S. V. Selección de hongos antagonistas para el control biológico de Botrytis cinerea en viveros forestales en Chile. Bosque, 27 (2): $126-134,2006$.

PICCININ, E.; PASCHOLATI, S. F. Efeito de Saccharomyces cerevisiae no controle de Botrytis cinerea em mudas de eucalipto. In: Congresso Brasileiro de Fitopatologia, 28, 1995. Fitopatologia Brasileira, v. 20, suplemento, p. 385.1995.

QUIROGA, E. N.; SAMPIETRO, A. R.; VATTUONE, M. Screening antifungal activitis of selected medicinal plants. Journal of Ethnopharmacology, v. 74, p. 89 - 96, 2001.

SANFUENTES, E.; FERREIRA, F. A. Fungos para a supressão de Botrytis cinerea em mudas de eucalipto. In: Congresso Brasileiro de Fitopatologia, 26, 1996. Fitopatologia Brasileira, v. 21, suplemento, p. 281. 1996.

SCHULTZ, B. Doenças bióticas e abióticas em Eucalyptus benthamii Maiden. 109 f. Dissertação (Mestrado em Ciência Florestal) - Universidade Federal do Paraná, Curitiba, 2012. (No prelo).

SILVA, F. de A. S. e.; AZEVEDO, C. A. V. de. Principal Components Analysis in the Software AssistatStatistical Attendance. In: WORLD CONGRESS ON COMPUTERS IN AGRICULTURE, 7, Reno-NVUSA: Anais... American Society of Agricultural and Biological Engineers, 2009.

SUTTON, J.; PENG, G.; Biocontrol of Botrytis cinerea in strawberry leaves. Phytopathology 83: 615 621, 1993. 
